\title{
The effect of temporal single alternation on learned increases in hippocampal unit activity in classical conditioning of the rabbit nictitating membrane response
}

\author{
FRED K. HOEHLER and RICHARD F. THOMPSON \\ University of California, Irvine, California 92717
}

\begin{abstract}
Rabbits were trained with a temporal single-alternation schedule in which reinforced (CS-US) trials were regularly alternated with nonreinforced (CS-alone) trials. Thus, CS-US trials were invariably preceded by CS-alone trials and CS-alone trials were invariably preceded by CS-US trials. In agreement with previous research, there was no evidence of behavioral discrimination; that is, conditioned nictitating membrane responses were no larger on CS-US trials than on CS-alone trials. In contrast, hippocampal multiple unit activity showed (1) greater conditioned increases on CS-US trials and (2) lowered pre-CS levels prior to CS-US trials. In a second experiment, CS-alone trials were replaced by "dummy" trials on which no stimuli were presented. There was no difference in pre-"CS" activity between CS-US and "dummy" trials, indicating that the effect shown in the first experiment was not produced by unlearned effects of US presentation. These results support the notion of an important role for the hippocampus in "working" memory.
\end{abstract}

Results of a recent series of studies from this laboratory strongly implicate the hippocampus in associative learning. Specifically, hippocampal neuron activity increases markedly over the course of classical conditioning of the rabbit nictitating membrane (NM) response. This pattern of increased unit activity is predictive of behavioral learning over the course of training and, within trials, actually predicts the amplitude-time course of the learned behavioral response (Berger, Alger, \& Thompson, 1976; Berger \& Thompson, 1978a, 1978b, 1978c; Berry \& Thompson, 1978, 1979; Thompson, Berger, Cegavske, Patterson, Roemer, Teyler, \& Young, 1976). Indeed, the topographies of the hippocampal and behavioral responses become highly correlated with training and are both strongly and similarly influenced by the CS-US interval, with the NM response peak always occurring near the point of the US onset and the hippocampal response preceding the behavioral response by about $40 \mathrm{msec}$ (Hoehler \& Thompson, 1980). In view of these results and the effects of hippocampal lesions on behavioral learning tasks, we suggested (Hoehler

Supported by research grants from NIMH (MH26530), NIH (NS 23368), NSF (BMS 75-00453), the McKnight Foundation, and NIMH Postdoctoral Fellowship MH 05041 to F.K.H. This work was brought to completion while the second author (R.F.T.) was a fellow of the Center for Advanced Study in the Behavioral Sciences, Stanford, California, with the support of Center funds and funds from NIMH (5T 32 MH 14581-03) and NSF (BNS 7622943 AO2). We thank Carol Cooper for histology and Michael Ross for assistance. F. K. Hoehler's current address: Department of Physical Medicine and Rehabilitation, California College of Medicine, University of California, Irvine, California 92717.
\& Thompson, 1980) that the function of the hippocampus might involve the marking of biologically important temporal locations in memory, i.e., the hippocampus might play an important role in "shortterm memory," in the processing of internal cues based on stimulus aftereffects.

In a recent review of the effects of hippocampal lesions on learning, Olton, Becker, and Handelmann (1979) propose a very similar view that the hippocampus plays a critical role in "working" memory, a term used by Honig (1978) to refer to a process in animal learning analogous to human short-term, or primary, memory. Specifically, in working memory tasks (e.g., delayed matching to sample), stimulus information is useful for only one trial, in contrast to "reference" memory tasks, where information is useful for many trials and usually for the entire experiment (Honig, 1978). A similar view of possible hippocampal involvement in memory processes was suggested earlier by Douglas (1967). "Working"' memory contains an important temporal component, while "reference" memory does not.

O'Keefe and Nadel (e.g., 1978) have developed a rather different theory implicating the hippocampus in the formation of a "spatial-cognitive map" of the environment. In the context of classical conditioning, it would seem important to examine hippocampal unit activity in paradigms where no spatial cues are present. O'Keefe and Nadel (Note 1) have suggested that in simple acquisition of a classically conditioned response, environmental context can provide spatialcontextual cues, which might result in increased 
hippocampal unit activity during conditioning in our studies. In the terms of Olton et al. (1979) and Honig (1978), simple acquisition of a classically conditioned response involves reference memory.

Temporal single-alternation (SA) in classical conditioning of the rabbit NM response is a task that involves no spatial or contextual cues whatever, requires the animal to process internal cues based only on the aftereffects of a prior stimulus (our notion), and involves working memory (Honig, 1978; Olton et al., 1979) in the sense that the animal must make use of information from the immediately preceding trial. In the SA paradigm, reinforced (R) and nonreinforced $(\mathrm{N})$ trials are regularly alternated so that $\mathbf{R}$ trials always precede $\mathbf{N}$ trials and $\mathbf{N}$ trials always precede $\mathrm{R}$ trials. This procedure readily produces patterning behavior (greater response strength or frequency on $\mathbf{R}$ trials) in preparations as diverse as instrumental appetitive conditioning in rats (Capaldi, Veatch, \& Stefaniak, 1966), instrumental avoidance conditioning in goldfish (Gonzalez, 1972), and classical conditioning of the human galvanic skin response (Longnecker, Krauskopf, \& Bitterman, 1952). It might be noted that one of the clearest effects of hippocampal lesions on behavior is on alternation behavior (e.g., Douglas, 1975; Isaacson, 1974; Kimble, 1975).

Curiously, in classical conditioning of the rabbit's NM response, SA patterning behavior does not seem to occur (Frey, 1969; Leonard \& Theios, 1967). Apparently, SA patterning behavior can only be produced when the rabbits are trained with differential intertrial intervals such that the $\mathrm{N}$ trials follow the preceding $\mathrm{R}$ trials by a short (e.g., 10-sec) interval and the $\mathrm{R}$ trials follow the preceding $\mathrm{N}$ trials by a long (e.g., 60-sec) interval (Hoehler \& Leonard, 1973). This does not result from any apparent speciesspecific factor, since albino rabbits can produce appropriate SA patterning behavior when trained in a classical appetitive situation (Poulos, Sheafor, \& Gormezano, 1971).

In view of the fact that rabbits do show SA patterning behavior with certain paradigms and/or response systems, it seems reasonable to assume that the associative characteristics of stimulus aftereffects are, in fact, registered in memory during SA training in the classical conditioning NM paradigm, even though these aftereffects do not have sufficient strength to influence differentially the NM response. If our view of hippocampal function in memory and the closely related view of Olton et al. (1979) has merit, then we might expect to see a differential neural response develop in the hippocampus over the course of SA training. This is a particularly stringent prediction in the sense that we expect a differential hippocampal response in the absence of a differential behavioral response. There seems to us to be no conceivable way that a "spatial map" hypothesis of hippocampal function could lead to this prediction.

\section{EXPERIMENT 1}

This experiment was based on the assumption that any associative processing effects occurring during SA training might manifest themselves as differential hippocampal activity in the CS period, even if there was no sequential control of the behavioral response. Therefore, hippocampal multiple-unit activity was recorded during classical conditioning of the rabbit's NM response with an SA schedule.

\section{Methods}

Data from 10 albino New Zealand rabbits are reported here. General methods of surgery, conditioning, data analysis, and histology were the same as those reported previously (e.g., Berger \& Thompson, 1978a; Hoehler \& Thompson, 1980; Thompson, Berger, Berry, \& Hoehler, 1980). Briefly, subjects were anesthetized and stainless steel microelectrodes $(5-\mu$ tip diameter, $50 \mu$ shaft exposed) were chronically implanted in the CA1 layer of the left dorsal hippocampus. Electrodes were localized both with stereotaxic coordinates $(4.5 \mathrm{~mm}$ caudal and $5.5 \mathrm{~mm}$ lateral to bregma) and with physiological recording during implantation. The electrode was then cemented to the skull with screws and dental acrylic with leads soldered to a permanently implanted headstage.

Seven to 10 days after surgery, all subjects received one session of adaptation to the apparatus followed by three daily sessions of classical conditioning of the NM response with a schedule of alternating $\mathbf{R}$ (CS-US) and $\mathrm{N}$ (CS-alone) trials. The animals were restrained in a Plexiglas box within a soundproof chamber and wore headgear containing the airpuff outlet, first-stage FET amplifiers, and the NM transducing system. The left eyelids were held open to facilitate reception of the airpuff US $\left(210 \mathrm{~g} / \mathrm{cm}^{2}, 100 \mathrm{msec}\right)$, while the tonal US $(1,000 \mathrm{~Hz}, 85 \mathrm{~dB}, 350 \mathrm{msec})$ was delivered by a speaker mounted in front of the subject. On each day of conditioning, the subjects received $56 \mathrm{R}$ trials and $56 \mathrm{~N}$ trials with CS-US onset intervals of $250 \mathrm{msec}$ and intertrial intervals of $60 \mathrm{sec}$.

Neural activity was amplified, recorded on tape, and subsequently band-pass filtered $(500-5,000 \mathrm{~Hz})$ and analyzed using a pulse-height discriminator set to maintain a mean spontaneous level of 30-40 spikes/sec. A PDP-12 computer system was used to count the number of pulses in successive 3-msec time bins throughout individual trials. Data were then averaged over the entire day of training and cumulated into bins of $24 \mathrm{msec}$. Ten of these bins occurring prior to the CS period were designated pre-CS bins, while the 10 bins occurring in the CS and the US period were designated CS and US bins, respectively. The amount of hippocampal multiple unit activity in each bin was expressed as a standard score based on the geometric mean of the standard deviations of the 10 pre-CS bins of the $\mathrm{R}$ - and N-trial poststimulus histograms. The amplitude-time course of the NM response was measured with a minitorque potentiometer, calibrated such that $1 \mathrm{~mm}$ of $\mathrm{NM}$ extension equaled $2 \mathrm{~mm}$ of movement on the polygraph, digitized and stored in the computer for subsequent analyses.

After behavioral training, the subjects were anesthetized and perfused through the heart with $.9 \%$ saline followed by $10 \%$ Formalin. Verification of electrode placement was made with enlarged photographs and standard stains of frozen sections of the brain in conjunction with a Prussian blue reaction for iron deposits 
left from dc current $(100 \mu \mathrm{A}, 1 \mathrm{sec})$ made through the electrode tip. All data reported here were from subjects with electrode tips in or near the CA1 pyramidal cell layer of the dorsal hippocampus.

\section{Results and Discussion}

All animals developed clear conditioned NM responses to tone by the 3rd day of training. The effect of the SA paradigm on the conditioned NM response is shown in the upper portion of Figure 1A, which displays the Day 3 CR and UR topographies averaged over all animals for $\mathbf{R}$ and for $\mathbf{N}$ trials separately. Mean NM response amplitudes in the last 10 th of the CS period (the period most likely to show a difference if any exists) are plotted over the 3 days of training in the upper portion of Figure 2A. As is evident from Figures 1 and 2, there is no differential effect of a preceding $\mathrm{R}$ or $\mathrm{N}$ trial [Day 3: $\mathrm{t}(9)=$ $.38, \mathrm{p}>.20]$. These results are in agreement with previous data (Frey, 1969; Hoehler \& Leonard, 1973; Leonard \& Theios, 1967) showing that the conditioned NM response is unaffected by the SA schedule. There is, obviously, a substantial differential effect of the airpuff US on the NM response in the US period within a trial (see Figure 1), as would be expected since on $\mathbf{R}$ trials the airpuff occurs and elicits a UR whereas on $\mathrm{N}$ trials there is no airpuff.

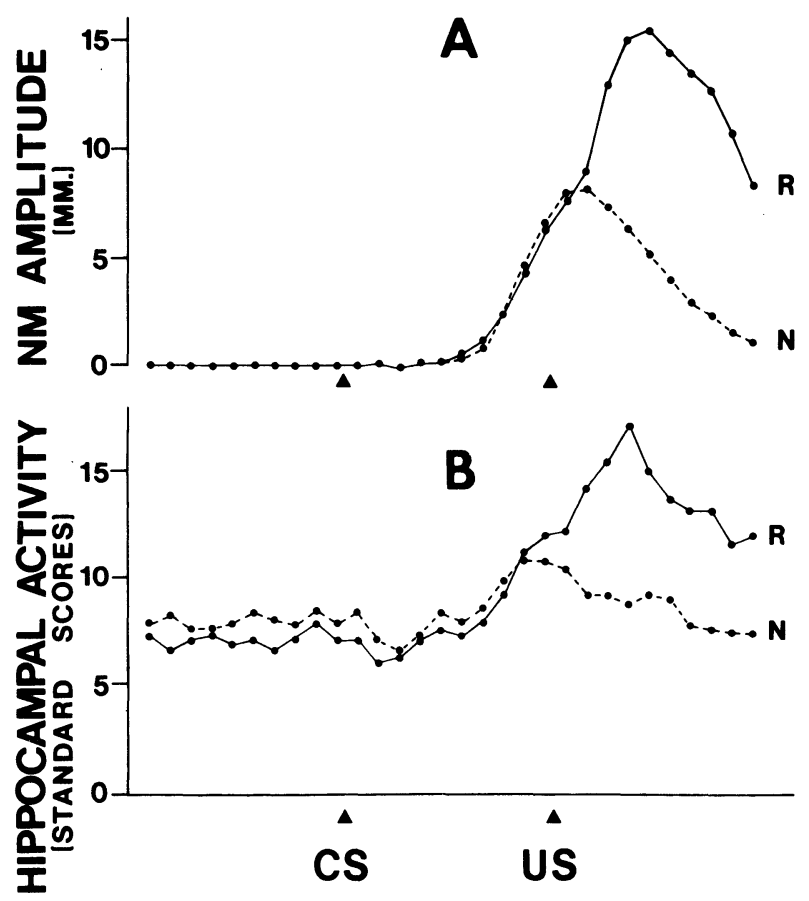

Figure 1. Averaged topographies of the NM response (upper panel) and the hippocampal multiple-unit response (lower panel) averaged across all subjects on Day 3 of single-alternation training. CS-US or reinforced (R) trials: solid lines. CS-alone or nonreinforced $(\mathrm{N})$ trials: broken lines. Triangles indicate $\mathrm{CS}$ and US onsets. Each point represents the average NM amplitude or number (standard scores) of hippocampal unit spikes during a 24-msec period.

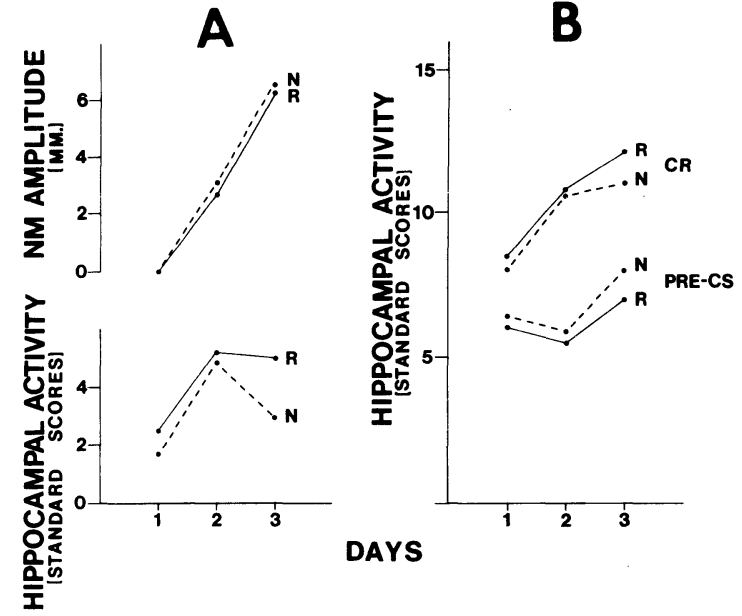

Figure 2. (A) Amplitude of the NM response during the last 10th of the CS period (upper panel) and the increase in hippocampal unit activity as indicated by the standard score of the last 10th of the CS period minus the mean standard score of the entire pre-CS period (lower panel). (B) Standard scores of hippocampal unit activity during the last 10th of the CS period (CR) and the entire pre-CS period. CS-US or reinforced (R) trials: solid lines. CS-alone or nonreinforced $(\mathrm{N})$ trials: broken lines.

In marked contrast to the NM response and in accordance with our prediction, there is a significant effect of the SA schedule on conditioned increases in hippocampal unit activity. The lower half of Figure 1 shows standard scores of neural unit activity plotted over 10ths of the pre-CS, CS, and US periods averaged over all animals separately for $\mathbf{N}$ and $\mathbf{R}$ trials on Day 3 of training. All animals developed conditioned increases in hippocampal unit activity with onset latencies shorter than the onset of the conditioned NM response, in agreement with previous reports from this laboratory (e.g., Berger \& Thompson, 1978a; Hoehler \& Thompson, 1980). The SA paradigm resulted in two distinct effects on this conditioned increase in hippocampal unit activity. First, neural unit activity in the pre-CS period is significantly lower on $\mathrm{R}$ trials than on $\mathrm{N}$ trials [ $\mathrm{t}(9)=$ $2.89, \mathrm{p}<.05]$. Second, during the last 10 th of the CS period, unit activity is significantly higher on $R$ trials than on $\mathrm{N}$ trials $[\mathrm{t}(9)=2.40, \mathrm{p}<.05]$.

These effects are shown in Figure 2B, which plots the standard scores of hippocampal unit activity for $\mathrm{N}$ and $\mathrm{R}$ trials for the entire pre-CS period, averaged over all animals for each of the 3 days of training (pre-CS), and similarly for the last 10th of the CS period (CR). These two differential effects of the SA schedule clearly develop over the course of training. The differences between the unit activity in the last 10th of the CS period and the pre-CS period for $\mathrm{N}$ and $\mathrm{R}$ trials (i.e., the difference between the two $\mathrm{N}$ curves and the difference between the two $R$ curves in Figure 2B) are plotted in Figure 2A, lower panel. A clear difference between $\mathbf{R}$ and $\mathbf{N}$ trials develops 
on the 3rd day of training with this difference score measure $[\mathrm{t}(9)=5.68, \mathrm{p}<.01]$.

There was some indication that hippocampal unit activity in individual subjects tended preferentially to display one or the other of the two effects (pre-CS and last 10th of CS changes), since the correlation coefficient between the pre-CS effect (N-trial standard scores greater than R-trial standard scores) and the CS-period effect (R-trial standard scores greater than N-trial standard scores) was -.61 , but this negative relationship was at borderline statistical significance $[\mathrm{t}(8)=2.18, \mathrm{p}=.06]$.

The two effects of the SA paradigm on conditioned increases in hippocampal unit activity standard scores-pre-CS levels greater on $\mathbf{N}$ trials than on $R$ trials and last 10th of CS period greater on $R$ trials than on $\mathrm{N}$ trials - are clear. However, it could be argued that these effects are due to nonassociative factors rather than being "learned" differential responses to the sequential cues contained in the SA schedule. In particular, $\mathbf{N}$ trials occur after an airpuff at an interval just half as long as is the case for $\mathbf{R}$ trials. Therefore, Experiment 2 was planned to test the possibility that the differential effects of the SA paradigm on conditioned increases in hippocampal unit activity might have resulted from an unlearned response to stimulus aftereffects.

\section{EXPERIMENT 2}

As indicated above, the results of Experiment 1 might be explained in terms of unlearned long-term effects of the airpuff US. In an SA schedule with a 60 -sec intertrial interval, $N$ trials occur $60 \mathrm{sec}$ after the last airpuff while $R$ trials occur $120 \mathrm{sec}$ after the last airpuff. This might account for the different levels of pre-CS hippocampal multiple-unit activity observed. It perhaps could also be assumed, although there is no particular reason to do so, that the population of active units in the hippocampus might tend to be less refractory during a period of lower spontaneous activity. If this were the case, then the greater increase in unit activity in the last 10th of the CS period on $R$ trials (see Figure 1) might simply be secondary to a lower level of pre-CS activity on $\mathbf{R}$ trials (see Figure 1), which in turn might be due to nonassociative factors, as noted above. Therefore, in Experiment 2, a group of rabbits were trained with continuous reinforcement at intertrial intervals of $120 \mathrm{sec}$ and spontaneous hippocampal activity was recorded during the intertrial interval. If the pre-CS effects seen in Experiment 1 resulted from long-term unlearned responses to the airpuff US, then these effects should also occur in the absence of $\mathrm{N}$ trials.

\section{Methods}

Four subjects were used in Experiment 2. Methods were exactly the same as in Experiment 1 except that all $\mathbf{N}$ trials were replaced by "dummy" trials, during which multiple-unit activity was recorded but no stimuli were presented to the animal, in exactly the same time periods that the $\mathrm{N}$ trials were given in Experiment 1 .

\section{Results and Discussion}

The results of Experiment 2 are clear. First, all animals learned the conditioned NM response by Day 3 of training. The mean amplitude of conditioned and unconditioned NM response on Day 3 did not differ significantly from that of the group trained on the SA schedule in Experiment 1 [ts(12) < 1.68 , ps $>.10$ ]. In terms of hippocampal unit activity, the animals in Experiment 2 given continuous reinforcement showed no tendency to exhibit higher levels of unit activity in the pre-CS period on "dummy" $\mathbf{N}$ trials than on $\mathbf{R}$ trials $(t<1)$. Table 1 compares the hippocampal unit standard scores on Day 3 of training for the pre-CS period on N (and "dummy" $\mathrm{N})$ and on R trials between the SA animals of Experiment 1 and the continuous reinforcement animals of Experiment 2 . The two groups differed significantly only in terms of the difference score: pre-CS (R) minus pre-CS $(\mathrm{N})$. This difference score itself was, of course, significant only in Experiment 1, as noted above, where the level of unit activity in the pre-CS period was higher on $\mathrm{N}$ trials than on $\mathrm{R}$ trials.

Table 1 also compares the increases in hippocampal unit activity on Day 3 in the CS and UCS periods, relative to the pre-CS levels for animals of the two experiments on $R$ trials. (Animals in Experiment 2 had no actual CS-alone $\mathrm{N}$ trials.) These conditioned increases in hippocampal unit activity in the CS and UCS periods are quite similar for the two experiments. This result indicated that learned increases in hippocampal unit activity on $R$ trials did not differ in the two experiments. In other terms, the occurrence of $\mathrm{N}$ trials in Experiment 1 did not greatly affect the conditioned increases in hippocampal activity on $\mathbf{R}$ trials. This result illustrates the very close comparability of the animals in Experiments 1 and 2 in terms of overall conditioned increases on paired (R) trials. It also suggests that the major effect of the SA paradigm in the CS period may be

Table 1

Comparisons of 10 Subjects Trained with Temporal SingleAlternation Schedule (Experiment 1) and 4 Subjects Trained with Continuous Reinforcement and "Dummy" Trials (Experiment 2) for Day 3 of Training

\begin{tabular}{lrr}
\hline & \multicolumn{2}{c}{ Experiment } \\
\cline { 2 - 3 } Hippocampal Standard Scores & \multicolumn{1}{c}{1} & \multicolumn{1}{c}{2} \\
\hline Pre-CS R Trials & 7.07 & $6.46 \dagger$ \\
Pre-CS N Trials & 8.06 & $6.13 \dagger$ \\
Pre-CS (R) minus Pre-CS (N) & -.99 & $.33^{*}$ \\
CR minus Pre-CS (R Trials) & 5.03 & $5.11 \dagger$ \\
UR minus Pre-CS (R Trials) & 12.40 & $12.18 \dagger$ \\
\hline
\end{tabular}

Note-CR = last 10th of the CS period. UR = the 10th of the US period that produced the maximum response.

${ }^{*}$ Experiment 1 vs. Experiment $2: t(12)=3.86, p<.01$.

tExperiment 1 vs. Experiment 2: nonsignificant (ts $<1$ ). 
a suppression of conditioned increases in hippocampal unit activity on $\mathrm{N}$ trials.

In sum, the continuously reinforced animals of Experiment 2 showed no tendency to produce higher levels of "pre-CS" hippocampal multiple unit activity on "dummy" $\mathrm{N}$ trials than on $\mathrm{R}$ trials. Consequently, the higher levels of pre-CS responding on $\mathrm{N}$ trials in the SA animals of Experiment 1 cannot be due to any persisting nonassociative effects of an $R$ trial airpuff on the succeeding $\mathrm{N}$ trial. Thus, the effects of the SA paradigm on hippocampal unit activity found in Experiment 1 must be due to learning.

\section{GENERAL DISCUSSION}

The results of these experiments indicate that, during classical conditioning of the rabbit NM response, (1) a temporal single-alternation (SA) schedule produces clear discrimination of the differential significance of $\mathrm{R}$ - and $\mathrm{N}$-trial stimulus aftereffects in hippocampal unit activity, and (2) this discrimination is due to associative rather than nonassociative factors. However, this neural discrimination is not translated into behavioral (NM) discrimination. The learned hippocampal discrimination has two separate aspects: (1) lower pre-CS background unit activity levels prior to $\mathrm{R}$ trials than prior to $\mathrm{N}$ trials, and (2) higher levels of unit activity in the CS periods on $\mathrm{R}$ trials than on $\mathrm{N}$ trials. Although it is possible that the higher R-trial CS-period activity is secondary to a lowered pre-CS background activity level just prior to $\mathrm{R}$ trials, our data argue against this possibility. Within animals, the relative occurrence of the two effects is negatively correlated $(-.61)$, indicating that a given animal tends to show one effect more than the other.

One possible explanation for the negative correlation between the pre-CS and CS effects might be that two different populations of hippocampal neurons are involved. In a single-unit analysis (Berger \& Thompson, 1978b; Thompson \& Berger, 1979) using antidromic stimulation of the fornix to identify pyramidal neurons of CA3 and CA1, it has been found that the within-trial conditioned increase in unit activity is generated largely by pyramidal neurons. Unidentified neurons tend to show either a withintrial decrease in activity or no change over the course of conditioning. Thus, the CS effect, the greater conditioned increase found here on $R$ trials (see Figure 1), might be due to pyramidal neurons, and the opposite pre-CS effect, greater background activity on $\mathrm{N}$ trials, might be due to interneurons. A single-unit analysis will be necessary to evaluate this possibility.

The pre-CS effect appears to result from associative processes based on stimulus aftereffects. This effect might be attributed to "arousal." The tonic level of hippocampal unit activity in the rabbit does, indeed, vary as a function of arousal, with moderate levels producing the least unit activity (Lidsky, Levine, $\&$ MacGregor, 1974). However, the absence of any pre-CS effect in Experiment 2 indicates that any such effect must be specifically conditioned to the aftereffects of stimulation. Thus, in the SA schedule, $\mathrm{R}$ trials may function as safety signals indicating that no US will be delivered until an $\mathbf{N}$ trial has been received, whereas $\mathrm{N}$ trials may function as warning signals indicating that a "safe" period is over. Again, this is a learning hypothesis involving conditioned changes in arousal level.

The CS effect, the fact that the SA schedule results in a significantly greater increase in hippocampal unit activity in the CS period on $R$ trials relative to $\mathrm{N}$ trials (Figure 1), clearly seems to be an associative effect. Because of the negative correlation between the pre-CS and the CS effects, it also seems unlikely that a conditioned "arousal" hypothesis regarding the pre-CS effect can account for the CS effect. On the 3rd day of training, the CS effect is maximal just before the onset of the airpuff US and begins to develop only in the last $100 \mathrm{msec}$ of the CS period (see Figure 1). It is as though the hippocampus gradually "realizes" the differential characteristics of the current trial but is unable to influence differentially the NM response.

A final point concerning the SA effect in this experiment relates to possible US/UR actions on hippocampal unit activity. In simple acquisition of the classically conditioned NM response, the first sign of a learned increase in hippocampal unit activity occurs in the US period, as early as the second trial of training (Berger \& Thompson, 1978a). Indeed, it was this fact that led us initially to suggest that the increased hippocampal unit activity was the first sign of the "engram"' in the brain (Thompson et al., 1976). The fact that there is a markedly greater increase in hippocampal unit activity in the US/UR period on $R$ trials relative to $N$ trials on Day 3 in Experiment 1 of the present study (see Figure 1) suggests that there is some type of interactive effect of the occurrence of the airpuff and/or the occurrence of the UR on the conditioned increase in unit activity. It is not a simple airpuff-evoked response or a necessary concomitent of the UR for two reasons: (1) Unpaired control animals may show a small initial increase in hippocampal unit activity in the US/UR period, but it does not grow over the course of unpaired training (Berger \& Thompson, 1978a); and (2) when paired trials are given under conditions where no behavioral learning occurs but a clear UR occurs (e.g., 50-msec forward interstimulus interval), little increase in hippocampal unit activity occurs in the US period (Hoehler \& Thompson, 1980). The present result, indicating a greater conditioned increase in the hippocampal unit activity in the US/UR period on $R$ trials, must be viewed only as suggestive because SA is, of course, a discrimination paradigm and the animals may, in fact, have learned 
to suppress hippocampal unit activity on $\mathrm{N}$ trials. The fact that the $\mathrm{R}$-trial hippocampal results are essentially identical in Experiments 1 and 2 supports this view. In any event, the possible interaction of the US/UR on conditioned increases in hippocampal unit activity suggested by the present result (Figure 1) merits further exploration with a more suitable paradigm.

As we noted above, the fact that classical conditioning of the behavioral NM response in rabbit does not itself show the effect of the SA paradigm is somewhat curious. However, several other paradigms involving remote stimulus aftereffects do clearly influence the rabbit classical conditioned NM response. One example is the partial reinforcement extinction effect in which CS-alone trials presented during acquisition produce increased resistance to extinction (Gibbs, Latham, \& Gormezano, 1978; Leonard, 1975). This phenomenon is most easily explained in terms of stimulus aftereffects of CS-alone or nonreinforced $(\mathrm{N})$ trials coming to predict the occurrence of subsequent CS-US or reinforced (R) trials during the acquisition phase (e.g., Capaldi, 1967). Another experimental paradigm which provides evidence for the role of stimulus aftereffects in classical NM conditioning is that of successive acquisitions and extinctions, in which successive acquisition and extinction sessions produce increasingly rapid reacquisition and increasingly rapid reextinction (Hoehler, Kirschenbaum, \& Leonard, 1973; Scavio \& Thompson, 1979; Smith \& Gormezano, 1965). A third example is latent inhibition, where presentations of the CS alone prior to conditioning substantially retard subsequent conditioning when the same CS is then paired with a US (Reiss \& Wagner, 1972; Solomon, Brenman, \& Moore, 1974). A final example is the blocking of the response to the new element in a compound stimulus when the other element had previously been reinforced (Kamin, 1968; Solomon, 1977). We consider it to be of great significance that damage to the hippocampus markedly impairs these phenomena in classical conditioning of the rabbit NM. Specifically, hippocampal lesions prevent the increasingly rapid extinction with repeated extinction sessions (Schmaltz \& Theios, 1972), they prevent the latent inhibition effect (Solomon \& Moore, 1975), and they prevent the blocking effect (Solomon, 1977). (To our knowledge, effects of hippocampal lesions on the partial reinforcement extinction phenomenon have not yet been examined in the rabbit NM preparation.) All these hippocampal lesion effects involve paradigms where behavior must be influenced by the remote aftereffects of stimuli, as noted above.

In terms of theoretical views of hippocampal function, the results of the present experiments support those theories that implicate the hippocampus in memory function. More specifically, our results are consistent with the hippocampus playing some kind of role in short-term or working memory (e.g., Douglas, 1967; Hoehler \& Thompson, 1980; Olton et al., 1979) and more generally being involved in memory storage and/or retrieval processes (Adey, 1977; Douglas, 1967; Gabriel, Foster, Drona, Saltwick, \& Stanton, 1980; Hirsh, 1974; Isaacson, 1974; Jarrard, 1973; John, 1967; Kesner, Dixon, Pickett, \& Berman, 1975; Kimble, 1968; Livesey, 1975; Milner, 1970; Moore, 1979; Olds, Disterhoft, Segal, Kornblith, \& Hirsh, 1972; Pribram, 1971; Routtenberg, 1972; Segal, 1973; Sokolov \& Vinogradova, 1975; Solomon, 1979; Vinogradova, 1975). In view of the fact that there are no conceivable differential spatial cues in the SA paradigm with classical conditioning of the NM response, it seems to us that our basic finding, that hippocampal neurons learn the differential significance of R-and $\mathrm{N}$-trial aftereffects, cannot be accounted for by the spatial map hypothesis of O'Keefe and Nadel (1978).

\section{REFERENCE NOTE}

1. O’Keefe, J., \& Nadel, L. Personal communication, 1979.

\section{REFERENCES}

ADEY, W. R. The sensorium and the modulation of cerebral states: Tonic environmental influences on limbic and related systems. In B. M. Wenzel \& H. P. Zeigler (Eds.), Tonic functions of sensory systems. Annals of the New York Academy of Science, 1977, 290, 396-420.

Berger, T. W., Alger, B. E., \& Thompson, R. F. Neuronal substrates of classical conditioning in the hippocampus. Science, 1976, 192, 483-485.

Berger, T. W., \& Thompson, R. F. Neuronal plasticity in the limbic system during classical conditioning of the rabbit nictitating membrane. I. Septum and mammillary bodies. Brain Research, 1978, 145, 323-346. (a)

BERGER, T. W., \& THOMPSON, R. F. Identification of pyramidal cells as the critical elements in hippocampal neuronal plasticity during learning. Proceedings, National Academy of Sciences, 1978, 75, 1572-1576. (b)

Berger, T. W., \& Thompson, R. F. Neuronal plasticity in the limbic system during classical conditioning of the rabbit nictitating membrane. I. Septem and mammillary bodies. Brain Research, 1978, 156, 293-314. (c)

Berry, S. D., \& Thompson, R. F. Prediction of learning rate from the hippocampal electroencephalogram. Science, 1978, 200, 1298-1300.

Berry, S. D., \& Thompson, R. F. Medial septal lesions retard classical conditioning of the nictitating membrane response in rabbits. Science, 1979, 205, 209-211.

CAPAldi, E. J. A sequential hypothesis of instrumental learning. In K. W. Spence \& J. T. Spence (Eds.), The psychology of learning and motivation (Vol. I). New York: Academic Press; 1967.

Capaldi, E. J., Veatch, R. L., \& Stefaniak, D. E. Stimulus control of patterning behavior. Journal of Comparative and Physiological Psychology, 1966, 61, 161-164.

Douglas, R. J. The hippocampus and behavior. Psychological Bulletin, 1967, 67, 416-442.

Douglas, R. J. The development of hippocampal function: Implications for theory and for therapy. In R. L. Isaacson \& K. H. Pribram (Eds.), The hippocampus (Vol. II). New York: Plenum, 1975.

FreY, P. W. Within and between-session CS intensity performance effects in rabbit eyelid conditioning. Psychonomic Science, 1969, 17, 1-2.

Gabriel, M., Foster, K., Orona, E., Saltwick, S. W., \& Stanton, M. Neuronal activity of cingulate cortex, anteroven- 
tral thalamus and hippocampal formation in discriminative conditioning: Encoding and extraction of the significance of conditional stimuli. In A. N. Epstein \& J. M. Sprague (Eds.), Progress in psychobiology and physiological psychology (Vol. 9). New York: Academic Press, 1980, in press.

Gibbs, C. M., Latham, S. B., \& Gormezano, I. Classical conditioning of the rabbit's nictitating membrane response: Effect of reinforcement schedules on response maintenance and resistance to extinction. Animal Learning \& Behavior, 1978, 6, 209-215.

Gonzalez, R. C. Patterning in goldfish as a function of magnitude of reinforcement. Psychonomic Science, 1972, 28, 53-55.

Hirsh, R. The hippocampus and contextual retrieval of information from memory: A theory. Behavioral Biology, 1974, 12, 421-444.

Hoehler, F. K., Kirschenbaum, D. S., \& Leonard, D. W. The effects of overtraining and successive extinctions upon nictitating membrane conditioning in the rabbit. Learning and Motivation, 1973, 4, 91-101.

Hoenler, F. K., \& Leonard, D. W. Classical nictitating membrane conditioning in the rabbit (Oryctolagus cuniculus). Single alternation with differential intertrial intervals. Journal of Comparative and Physiological Psychology, 1973, 85, 277-288.

Hoenle R, F. K., \& Thompson, R. F. Effect of the interstimulus (CS-UCS) interval on hippocampal unit activity during classical conditioning of the nictitating membrane response of the rabbit, Oryctolagus cuniculus. Journal of Comparative and Physiological Psychology, 1979, in press.

HonIG, W. K. Studies of working memory in the pigeon. In S. H. Hulse, W. K. Honig, \& H. Fowler (Eds.), Cognitive aspects of animal behavior. Hillsdale, N.J: Erlbaum, 1978.

Is AACson, R. L. The limbic system. New York: Plenum, 1974.

JARRARD, L. R. The hippocampus and motivation. Psychological Bulletin, 1973, 79, 1-12.

John, E. R. Mechanisms of memory. New York: Academic Press, 1967.

KAMIN, L. J. "Attention-like" processes in classical conditioning. In M. R. Jones (Ed.), Miami symposium on the prediction of behavior. Miami, Florida: University of Miami Press, 1968.

Kesner, R. P., Dixon, D. A., Pickett, D., \& Berman, R. F. Experimental animal model of transient global amnesia: Role of the hippocampus. Neuropsychologia, 1975, 13, 465-480.

Kimble, D. P. Hippocampus and internal inhibition. Psychological Bulletin, 1968, 70, 285-295.

Kimble, D. P. Choice behavior in rats with hippocampal lesions. In R. L. Isaacson \& K. H. Pribram (Eds.), The hippocampus (Vol. II). New York: Plenum, 1975.

LEONARD, D. W. Partial reinforcement effects in classical aversive conditioning in rabbits and human beings. Journal of Comparative and Physiological Psychology, 1975, 88, 596-608.

Leonard, D. W., \& Theors, J. Effect of CS-US interval shift on classical conditioning of the nictitating membrane in the rabbit. Journal of Comparative and Physiological Psychology, $1967,63,355-358$.

Lidsky, T. I., Levine, M. S., \& MacGregor, S. Hippocampal units during orienting and arousal in rabbits. Experimental Neurology, 1974, 44, 171-186.

LivesEY, P. J. Fractionation of hippocampal function in learning. In R. L. Isaacson \& K. H. Pribram (Eds.), The hippocampus (Vol. II). New York: Plenum, 1975.

Longnecker, D. D., Krauskopf, J., \& Bitterman, M. E. Extinction following alternating and random partial reinforcement. American Journal of Psychology, 1952, 65, 580-587.

Milner, B. Memory and the medial temporal regions of the brain. In K. H. Pribram and D. E. Broadbent (Eds.), Biological bases of memory. New York: Academic Press, 1970.

Moore, J. W. Brain processes and conditioning. In A. Dickinson \& R. A. Boakes (Eds.), Mechanisms of learning and memory: A memorial to Jerzy Konorski. Hillsdale, N.J: Erlbaum, 1979.

O'KeEFE, J., \& NADEL, L. The hippocampus as a cognitive map. New York: Oxford University Press, 1978.

Olton, D. S., Becker, J. T., \& Handelmann, G. E. Hippocam- pus, space, and memory. The Behavioral and Brain Sciences, 1979 , in press.

Olds, J., Disterhoft, J. F., Segal, M., Kornblith, C. L., \& HiRSH, R. Learning centers of rat brain mapped by measuring latencies of conditioned unit responses. Journal of Neurophysiology, 1972, 35, 202-219.

Poulos, C. X., She afor, P. J., \& Gormezano, I. Classical appetitive conditioning of the rabbit's (Oryctolagus cuniculus) jaw movement response with a single-alternation schedule. Journal of Comparative and Physiological Psychology, 1971, 75, 231-238.

Pribram, K. H. Languages of the brain: Experimental paradoxes and principles in neuropsychology. Englewood Cliffs, N.J: Prentice-Hall, 1971.

Reiss, S., \& WAgNer, A. R. CS habituation produces a "latent inhibition effect" but no active "conditioned inhibition." Learning and Motivation, 1972, 3, 237-245.

RoutTenberg, A. Memory as input-output reciprocity: An integrative neurobiological theory. Annals of the New York Academy of Sciences, 1972, 193, 159-174.

Scavio, M. J., \& Thompson, R. F. Extinction and reacquisition performance alternations of the conditioned nictitating membrane response. Bulletin of the Psychonomic Society, 1979, 13, 57-60.

SEgAL, M. Flow of conditioned responses in limbic telencephalic system of the rat. Journal of Neurophysiology, 1973, 36, 840-854.

Schmaltz, L. W., \& Theios, J. Acquisition and extinction of a classically conditioned response in hippocampectomized rabbits (Oryctolagus cuniculus). Journal of Comparative and Physiological Psychology, 1972, 79, 328-333.

Smith, M., \& Gormezano, I. Effects of alternating classical conditioning and extinction sessions on the conditioned nictitating membrane response of the rabbit. Psychonomic Science, 1965, 3, 91-92.

Sokolov, E. N., \& Vinogradova, O. S. (Eds.), Neuronal mechanisms of the orienting reflex. (N. M. Weinberger, trans.). Hillsdale, N.J: Erlbaum, 1975.

Solomon, P. R. Role of the hippocampus in blocking and conditioned inhibition of the rabbit's nictitating membrane response. Journal of Comparative and Physiological Psychology, 1977, 91, 407-417.

Solomon, P. R. Temporal versus spatial information processing theories of hippocampal function. Psychological Bulletin, 1979, in press.

Solomon, P. R., Brennan, G., \& Moore, J. W. Latent inhibition of the rabbit's nictitating membrane response as a function of CS intensity. Bulletin of the Psychonomic Society, 1974, $4,445-449$.

Solomon, P. R., \& Moore, J. W. Latent inhibition and stimulus generalization of the classically conditioned nictitating membrane response in rabbits (Oryctolagus cuniculus) following dorsal hippocampal ablations. Journal of Comparative and Physiological Psychology, 1975, 89, 1192-1203.

Thompson, R. F., \& BERgER, T. W. Responses of single hippocampal neurons during classical conditioning. Neuroscience Abstracts, 1979, 5, 325.

Thompson, R. F., Berger, T. W., Berry, S. D., \& Hoehler, F. K. The search for the engram. II. In D. McFadden (Ed.), Neural mechanisms in behavior: $A$ Texas symposium. New York: Springer-Verlag, 1980, in press.

Thompson, R. F., Berger, T. W., Cegavske, C. F., Patterson, M. M., Roemer, R. A., Teyler, T. J., \& Young, R. A. The search for the engram. American Psychologist, 1976, 31, 209-227.

Vinogradova, O. S. Functional organization of the limbic system in the process of registration of information: Facts and hypotheses. In R. L. Isaacson \& K. H. Pribram (Eds.), The hippocampus (Vol. II). New York: Plenum, 1975, 3-70.

(Received for publication August 13, 1979; revision accepted October 26, 1979.) 